\title{
Radiation Characteristics of a Square Pyramidal Horn Antenna with Tapered DielectricE-Plane Boundary Walls Loaded With Periodic Conducting Strips
}

\author{
Dr. Stephen Rodrigues \\ Department of Instrumentation, Cochin University of Science \& Technology, Cochin-682022, India
}

\begin{abstract}
A rectangular pyramidal horn antenna fabricated with tapered dielectric E-plane boundary walls whose inner surface is periodically loaded with thin conducting strips is investigated. For better impedance matching, at the throat region of the horn antenna, $3 \mathrm{~cm}$ portion is metallised. The radiation characteristics of this horn antenna are compared with that of an identical conventional horn antenna with conducting E-plane boundary walls. Considerable improvement in the E-plane radiation characteristics is observed. As H-plane boundary walls are not modified, no change in the H-plane radiation characteristics is observed. However, the conventional horn antenna shows slightly better impedance matching than the test horn antenna.
\end{abstract}

Keywords: Antennas, Dielectric loaded horns, Electromagnetic waves, Feed horn antennas, Microwave antennas,

\section{Introduction}

Metallic corrugated horns are superior as feed horns with their excellent radiation characteristics. However, these horns are difficult to manufacture and are heavy. Alternate feed horns with conical and square pyramidal profile with conducting strip loaded dielectric walls that simulates all the radiation characteristics of identical metallic corrugated horns are reported. In simulated feed horn antennas reported $[5,6,7,10]$ the Eplane boundary walls were of uniform thickness after the tapered throat profile region used for impedance matching. Moreover, in these horns, at the throat region, immediately after the waveguide section only $1 \mathrm{~cm}$ portion of the throat is metallised.In the presentpaper,a square pyramidal horn with $3 \mathrm{~cm}$ metallisation at the throat region and tapered dielectric E-plane boundary walls that are loaded with periodic structure of conducting strips on inner sides is investigated. The radiation characteristics of the present test horn (TH antenna) antenna are compared with that of an identical conventional horn ( $\mathrm{CH}$ antenna) antenna.

\section{Fabrication Details}

The TH antenna is a square pyramidal horn. The aperture dimensions are $a_{1}=b_{1}=5.9 \mathrm{~cm}$ and the $\mathrm{E}$ and $\mathrm{H}$ - plane slant lengths are $\rho_{\mathrm{E}} \rho_{\mathrm{H}}=12.8 \mathrm{~cm}$. The corresponding semi flare angles in the above planes are $\psi_{\mathrm{E}}=\psi_{\mathrm{H}}=25^{\circ}$. At the throat region, $3 \mathrm{~cm}$ portion is metallised. After this metallised portion, the thickness of the dielectric plate is $0.75 \mathrm{~cm}$. This is then gradually tapered to a thickness of $0.55 \mathrm{~cm}$ at the aperture of the horn so that the mean thickness of $0.65 \mathrm{~cm}$ satisfies balanced hybrid mode condition approximately at the frequency 9.2 GHz. The entire remaining inner surface of the E-plane walls are then periodically loaded with thin conducting strips at a period $d=0.061 \lambda$ and $\mathrm{a} / \mathrm{d}=0.5$, where $\lambda$ is the free space wavelength at the design frequency.

\section{Experimental Results.}

Typical return loss variation of the TH antenna with frequency is shown in figure 1. In the entire Xband frequency region the return loss is better than $-15.69 \mathrm{~dB}$. For all the frequencies above this, in the entire $\mathrm{X}$ - band, the return loss is well within the tolerable limits. 


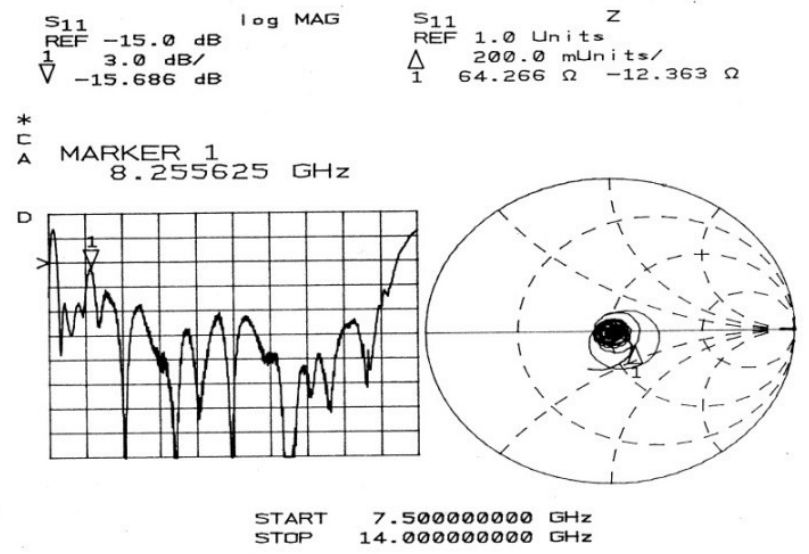

Figure 1.The return loss variation of the TH antenna with frequency

The typical E- plane radiation pattern of the TH antenna at the design frequency, $9.2 \mathrm{GHz}$, is presented in figure 2. For comparison, the E- plane radiation pattern of the identical $\mathrm{CH}$ antenna at $9.2 \mathrm{GHz}$ is also plotted in the same graph. The radiation pattern of the new strip loaded TH antenna is narrow without any side lobes in the main beam. The H- plane radiation patterns of this horn are found to be identical to the $\mathrm{H}$ - plane radiation patterns of the identical $\mathrm{CH}$ antenna. Hence they are not presented here. It is also observed that the E-plane radiation patterns of this horn, in the entire $\mathrm{X}$ - band of frequency, are narrower than its $\mathrm{H}$ - plane radiation patterns.

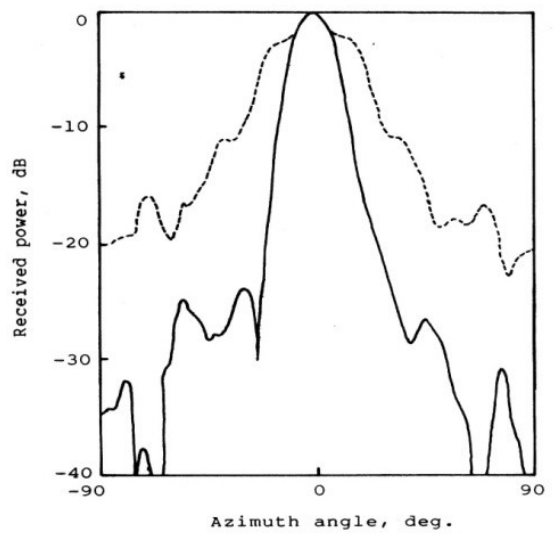

Figure 2. The E-plane radiation patterns of the $\mathrm{TH}$ antenna and the $\mathrm{CH}$ antenna
TH antenna
$\mathrm{CH}$ antenna

In figure 3 , the variation of side lobe and back lobe levels of the present $\mathrm{TH}$ antenna and the conventional $\mathrm{CH}$ antenna is shown. Compared to the $\mathrm{CH}$ antenna, the side lobe and back lobe levels of the $\mathrm{TH}$ antenna are found to be considerably improved. The side lobe level of the TH antenna is found to be better than $-20 \mathrm{~dB}$ in the entire $8 \mathrm{GHz}$ to $12 \mathrm{GHz}$ frequency range. As shown in figure 4, the cross polarisation level of the $\mathrm{TH}$ antenna is better than $-25 \mathrm{~dB}$ in the entire $8.5 \mathrm{GHz}$ to $12 \mathrm{GHz}$ frequency range. Moreover, its variation with frequency is also found to be smoother than that of the $\mathrm{CH}$ antenna.

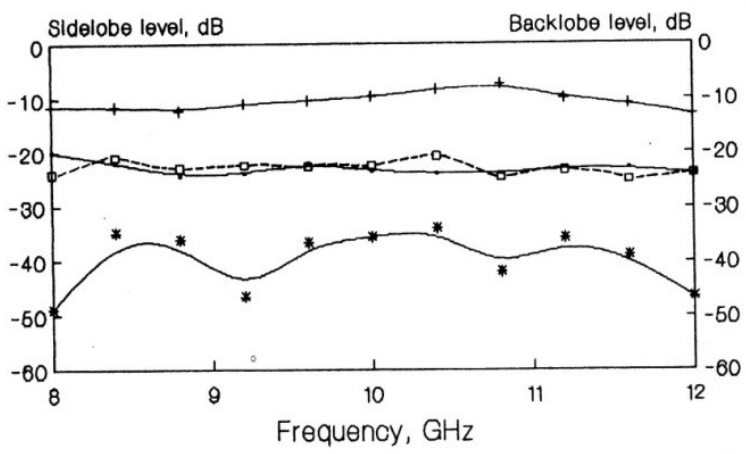

Figure3. Variation of side lobe and back lobe levels of TH antenna and $\mathrm{CH}$ antenna with frequency $\rightarrow$ Side lobe level $\mathrm{TH}+$-Side lobe level $\mathrm{CH}$ 

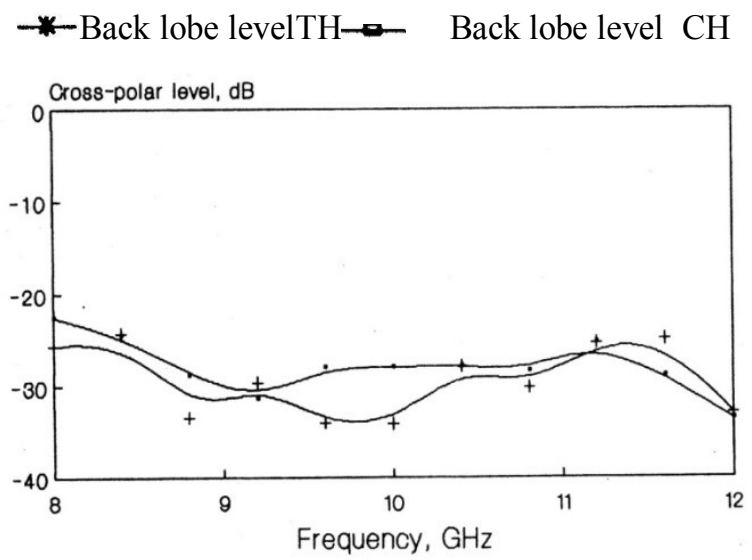

Figure 4. Variation of cross polarisation levels of TH antenna and $\mathrm{CH}$ antenna with frequency

$$
\rightarrow \mathrm{TH}+\mathrm{CH}
$$

Frequency response of the 3- $\mathrm{dB}$ and $10-\mathrm{dB}$ beam widths of $\mathrm{TH}$ antenna compared with that of the $\mathrm{CH}$ antenna are shown in figure 4 . In the entire $\mathrm{X}$ - band frequency region, the 3- $\mathrm{dB}$ beam width is found to be decreasing with increase of frequency. However, above $10.4 \mathrm{GHz}$, the $10-\mathrm{dB}$ beam widths are found to be widened with increase of frequency.

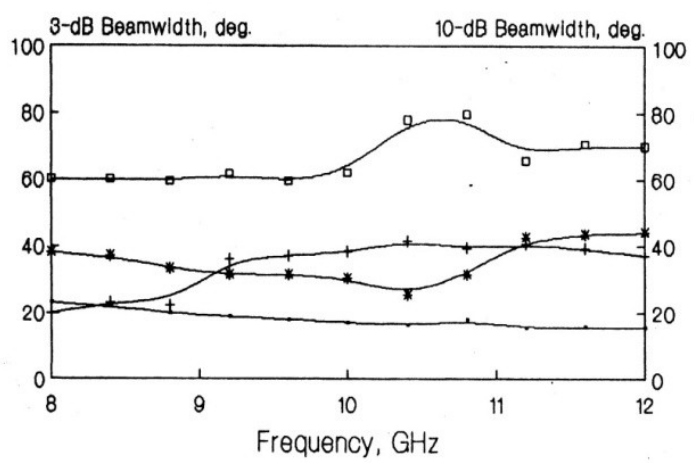

Figure 5. Frequency response of the $3-\mathrm{dB}$ and $10-\mathrm{dB}$ beam widths of $\mathrm{TH}$ antenna and the $\mathrm{CH}$ antenna

$\underset{*-10-\mathrm{dB} \text { beam width TH } \quad+3 \text {-dB beam width } \mathrm{CH}}{\rightarrow-10-\mathrm{dB} \text { beam width } \mathrm{CH}}$

The typical variation of gain with frequency of $\mathrm{TH}$ antenna and $\mathrm{CH}$ antenna are given in figure 6. In the entire frequency rangeof $8.5 \mathrm{GHz}$ to $12 \mathrm{GHz}$, the gain of the present horn is better than that of the conventional $\mathrm{CH}$ antenna and it is found to be gradually increasing with frequency.

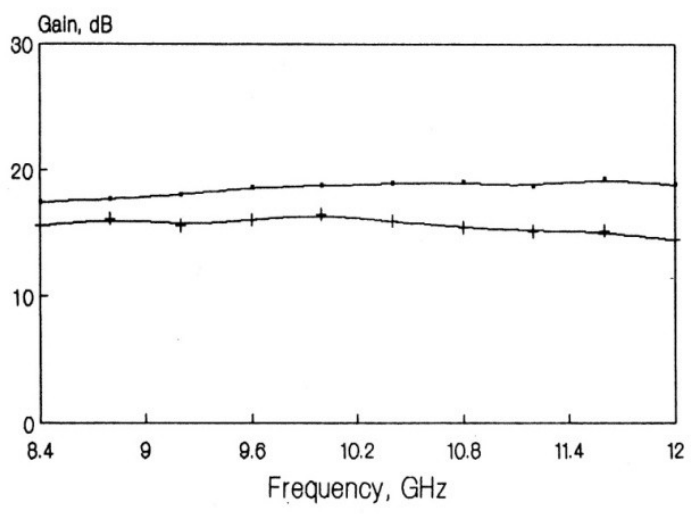

Figure 6. Variation of gain of horns $\mathrm{TH}$ and $\mathrm{CH}$ with frequency

$$
\rightarrow \mathrm{TH}+\mathrm{CH}
$$




\section{Conclusion}

From the comparative study of the radiation characteristics of the new TH antenna and the identical $\mathrm{CH}$ antenna it is evident that the radiation characteristics of the present TH antenna fabricated with tapered dielectric E- plane walls, are much better than that of the $\mathrm{CH}$ antenna except the return loss characteristics. However, the return loss characteristics of the new TH antenna are well within the tolerable limits.

\section{References}

[1] S .Silver, "Microwave Antenna Theory and Design ", McGraw Hill Book Co., New York, 1949.

[2] R.E Collin and E.J Zucker, “Antenna Theory Part- I “, McGraw Hill Book Co., New York, 1969.

[3] E. Lier and T.S Petterson, "The Strip Loaded Hybrid Mode Feed Horn”, IEEE Trans. Antennas Propagat. Vol.AP-36, No. 9, pp. 1086- 1088, Sept.1987

[4] E. Lier and P.S Kildal, "Soft and Hard Horn Antennas", ibid, Vol. 36, No.8, pp. 1152-1157, Aug. 1988

[5] S. Rodrigues, P.Mohanan and K.G Nair, "Simulated Corrugated Feed Horn Antennas", Proc. IEEE AP-S Intl. Symp. USA, 1990, pp.984-987

[6] S.Rodrigues, P.Mohanan and K.G Nair, “A Strip Loaded Feed Horn Antenna”, IEEE Microwave and Guided Wave Letters", Vol. 1, No.11, pp.318-319, Nov.1991

[7] S. Rodrigues, "Simulated Scalar Feed Horn Antenna with Exterior Tapered Throat Profile", IOSR Journal ofApplied Physics", Vol.3, Issue 5, Mar-Apr., 2013, pp. 92-96

[8] C. Dragone, "A rectangular horn of four corrugated plates “, IEEE Trans. Antennas. Propagat. Vol. AP - 33, No. 2, pp 160 - 164, Feb. 1985 .

[9] M.Narasimhan and V.V Rao, "Radiation from Wide Flare Corrugated E- Plane Sect oral Horn “, IEEE Trans. Antennas. Propagat. Vol. AP - 22, No. 2, pp $603-608$, July 1974.

[10] S.Rodrigues, "A Small Square Aperture Simulated Corrugated Feed Horn Antenna with Beam Symmetry", IOSR Journal of Electronics and Communication Engineering “, Vol.8, Issue 3, and Nov. - Dec. 2013.pp. 21-24

[11] S. Rodrigues, "Development of a New Reflecting Surface for Electromagnetic Waves", IOSR Journal of Applied Physics", Vol.1, Issue 6, Sep - Oct, 2012, pp. 55 - 58 